\title{
Siklus Tata Kelola Organisasi Badan Pemusyawaratan di Desa Sepakat, Kabupaten Kutai Kartanegara
}

\author{
Juliansyah Roy* dan Selly Swandari \\ Fakultas Ekonomi dan Bisnis, Universitas Mulawarman \\ Corresponding e-mail: juliansyah.roy@feb.unmul.ac.id \\ sellyswandari93@gmail.com
}

\begin{abstract}
.Abstract
The Law on Villages has shifted the position of the Village Consultative Body (BPD) as an element of village administration to become a village institution. As a village institution, the function and position of the BPD include the village legislature. This regulation also demands changes in organizational governance for BPD, particularly in Sepakat Village (Loa Kulu District, Kutai Kartanegara Regency). This encourages researchers to look at and provide recommendations related to the organizational governance of BPD in Sepakat. The approach used in this service is a qualitative-based descriptive analysis. The process here focuses on four elements. In the first topic of discussion is the organizational structure of the BPD in Sepakat Village, the second is the division of the main tasks and functions of each BPD member, the third includes the standard operating procedure (SOP) for implementing activities and the fourth is the supervision of the BPD. Through data collection with in-depth interviews, it designed the analysis model with five units (checking the data got, reducing data, applying data, namely data processing, analyzing, and drawing conclusions). to get an overview of the field. Practical ideas suggest that there should be regular supervision and training of human resources for BPD of Sepakat Village.
\end{abstract}

Kata kunci: Manajemen Organisasi, BPD, Desa Sepakat, Interview Mendalam, Perbaikan Tata Kelola

\section{Pendahuluan}

\subsection{Situasi Terkini}

Desa Sepakat merupakan Desa pemekaran dari Desa Loa Kulu Kota yang telah mengalami pergantian Kepala Desa sebanyak dua kali yaitu Pejabat sementara dan Kepala Desa terpilih. Secara umum keadaan topografi Desa Sepakat adalah dataran rendah dan merupakan daerah pertanian dan perkebunan. Desa Sepakat berpenduduk 2.135 jiwa dengan luas wilayah 162 km. Dengan klasifikasi perempuan 1.022 jiwa, laki-laki 1.113 jiwa dan terbagi dalam 601 kepala keluarga (BPS Kutai Kartanegara, 2020).

Perkembangan pelayanan kepada masyarakat dimulai ketika Tahun 2012 terjadi pemekaran Desa yakni Desa Loa Kulu kota memekarkan wilyahnya sebagian menjadi Desa Sepakat. Tahun pertama dimekarkan pemerintah Desa mempusatkan pelayanannya pada tempat / lokasi daerah RT. 05 dengan pengganggaran sewa tempat sebelumnya APBDes pertama disahkan dan dicairkan. Kemudian ketika tahun 2014 pembangunan Kantor Desa Sepakat selesai maka secara otomatis segala pelayanan administrasi juga dipindahkan yakni di Jalan Rapak Nyamuk RT. 01 hingga sekarang.

Dengan adanya berbagai rencana pembangunan strategis baik ditingkat regional maupun nasional yang akan dilaksanakan oleh Pemerintah Provinsi maupun Pemerintah Pusat akan menjadikan Kabupaten Kutai Kartanegara mendapat berbagai limpahan besar pembangunan 
yang strategis, misalnya: Rencana pembangunan Parit Peninggalan Penjajahan Jepang, Rencana pemanfaatan eks galangan kapal dan gedung Magazine, Rencana pembangunan Jembatan Loa Kulu, Rencana pembangunan Jalan tol yang melintas di Kecamatan Loa Kulu, dan Rencana pemindahan Ibu Kota RI ke Kalimantan Timur (Ilmi, 2021).

Memperhatikan proyeksi pembangunan seperti itu, maka Pemerintah Desa Sepakat perlu perhatian dalam menangkap peluang pembangunan terutama dalam mengantisipasi dan mensikapi perubahan-perubahan yang muncul sebagai dampak dari pembangunan tersebut (sebagai contoh Yusuf \& Elvira, 2016; Pradana \& Istriyani, 2020).

Berbagai permasalahan masih dihadapi oleh berbagai daerah, terutama Desa yang dominanmasih rentannya tingkat kemiskinan sebagai dampak dari internal maupun dampak global adalah tantangan ke depan yang perlu dipecahkan bersama melalui penyelenggaraan pemerintahan yang berpihak kepada rakyat yang didukung oleh lapisan masyarakat dan pihak yang terkait (Darma et al., 2021).

Tabel 1. Profile Aset di Desa Sepakat Tahun 2020

\begin{tabular}{llll}
\hline No & Uraian & Volume & Satuan \\
\hline 1. & Kas Desa/Kelurahan & 0 & $\mathrm{Ha}$ \\
& a. Tanah Bengkok & 0 & $\mathrm{Ha}$ \\
& b. Tanah Titi Sara & 0 & $\mathrm{Ha}$ \\
& c. Kebun Desa & 0 & $\mathrm{Ha}$ \\
& d. Sawah Desa & 0 & $\mathrm{Ha}$ \\
2. Lapangan Olahraga & 2,00 & $\mathrm{Ha}$ \\
3. Perantoran Pemerintah & 0,71 & $\mathrm{Ha}$ \\
4. Ruang Publik/ Taman Kota & 0 & $\mathrm{Ha}$ \\
5. Tempat Pemakaman Desa/umum & 1,50 & $\mathrm{Ha}$ \\
6. Tempat Pembuangan Sampah & 0,30 & $\mathrm{Ha}$ \\
7. Bangunan Sekolah/ Perguruan Tinggi & 1,00 & $\mathrm{Ha}$ \\
8. Petokoan & 0,49 & $\mathrm{Ha}$ \\
9. Fasilitas Pasar & 0 & $\mathrm{Ha}$ \\
10. Terminal & 0 & $\mathrm{Ha}$ \\
11. Jalan & 10,00 & $\mathrm{Ha}$ \\
12. Daerah Tangkapan Air & 11,00 & $\mathrm{Ha}$ \\
13. Usaha Perikanan & 25,00 & $\mathrm{Ha}$ \\
14. Sutet/Aliran Listrik tegangan air & 0 & $\mathrm{Ha}$ \\
Total Luas & $\mathbf{5 2 , 0 0}$ & $\mathrm{Ha}$ \\
\hline
\end{tabular}

Sumber: Milasari (2021).

Badan Usaha Milik Desa (BUMDes) merupakan lembaga usaha yang dimiliki Desa dalam upaya memperkuat perekonomian Desa dan dibentuk berdasarkan kebutuhan masyarakat dan potensi Desa. BUMDes merupakan bentuk kelembagaan Desa yang memiliki kegiatan menjalankan usaha ekonomi atau bisnis untuk memperoleh manfaat yang berguna bagi kesejahteraan masyarakat Desa (Dina et al., 2020; Faedlulloh, 2018). Desa mendirikan BUMDes bukanlah semata-mata untuk mencari keuntungan ekonomis atau laba, namun juga meliputi manfaat non ekonomi lainnya. Seperti yang diatur dalam Peraturan Menteri Desa Nomor 4 Tahun 2015 tentang Pendirian, Pengurusan dan Pengelolaan, dan Pembubaran Badan Usaha Milik Desa. Dengan hadirnya BUMDes sebagai lembaga usaha Desa yang lahir atas pertimbangan kebutuhan dan potensi Desa (Rahmawati, 2020). Tentu, ini sangat 
$\overline{\text { berpengaruh bagi Desa juga masyarakat di sekitarnya. Hasil dari pengelolaan BUMDes yang }}$ disebut keuntungan akan menjadi pemasukan semisal Pendapatan Asli Desa (PAD).

Desa Sepakat memiliki aset Desa berupa tanah untuk fasilitas umum. Tabel 1 menggambarkan jumlah BUMdes di Kutai Kartanegara tahun 2020, Jumlah BUMdes yang terbentuk di Desa terdapat 188. Jumlah Bumdes yang belum terbentuk di Desa terdapat 5 BUMdes, jumlah Bumdes yang aktif 109 BUMdes, dan jumlah BUMdes yang tidak aktif terdapat 84 BUMdes, untuk Desa Sepakat terdapat 1 BUMdes, dengan nama BUMdes Karya Mandiri.

Dalam Undang-Undang Nomor 6 Tahun 2014 tentang Desa pada pasal 54, dijelaskan bahwa musyawarah Desa merupakan forum pemusyawaratan yang diikuti oleh Badan Permusyawaratan Desa (BPD), Pemerintah Desa (PD), dan unsur masyarakat Desa yang bertujuan untuk memusyawarahkan hal yang bersifat strategis dalam penyelenggaraan Pemerintah Desa (Endah, 2018). Berkaitan dengan penyelenggaraan dalam pemerintahan di Desa, pemerintah Desa sebagai penggerak masyarakat untuk dapat berpartisipasi dalam pembangunan fisik Desa dan penyelenggaraan administrasi Desa, maka setiap keputusan yang diambil harus didasarkan atas musyawarah Desa untuk mencapai keputusan bersama.

Sebagai subjek pembangunan tentunya warga masyarakat hendaknya sudah dilibatkan untuk menentukan perencanaan pembangunan sesuai dengan kebutuhan objektif masyarakat yang bersangkutan (Zainurossalamia et al., 2021). Dalam artian, jika perencanaan pembangunan yang akan dilaksanakan dapat menyentuh langsung kebutuhan masyarakat, sehingga program perencanaan pembangunan Desa yang akan dicanangkan, masyarakat dapat berpartisipasi seoptimal mungkin. Ide-ide pembangunan harus didasarkan pada kepentingan masyarakat dalam memenuhi kebutuhannya yang menunjang terhadap pembangunan nasional (Mafruhah et al., 2018; Giampiccoli \& Saayman, 2018). Gagasan pembangunan Desa inilah yang akan ditampung oleh BPD dan akan dimufakatkan bersama dalam musyawarah pembangunan Desa, maka dapat direncanakan dengan baik antara pemerintah dengan masyarakat. Pada akhirnya, itu akan menumbuhkan prakarsa, swadaya masyarakat, dan partisipasi aktif nantinya pada saat pelaksanaan pembangunan Desa.

Oleh karena itu, perencanaan pembangunan desa akan dilaksanakan pada musyawarah pembangunan Desa antara pemerintah (Sulaiman et al., 2016). Lebih lanjut, pemerintah Desa dan BPD berfungsi untuk menampung dan menyalurkan aspiras masyarakat dalam memenuhi kebutuhan hidup dan penghidupannya. Dengan demikian, yang menjadi persoalan dalam hal ini apakah Badan Pemusyawaratan Desa telah benar-benar melaksanakan tugas pokok dan fungsinya dalam perencanaan pembangunan Desa sesuai dengan yang diamanatkan oleh undang-undang, ataukah ada faktor-faktor lain yang menunjang perencanaan pembangunan Desa.

\subsection{Problematika Mitra}

Undang-Undang Desa telah menggeser posisi BPD sebagai unsur penyelenggara pemerintahan desa menjadi lembaga Desa (Suharto, 2015). Sebagai lembaga Desa, fungsi dan kedudukan BPD sebagai lembaga legislatif Desa. BPD bertugas untuk menyalurkan aspirasi, merencanakan anggaran, dan mengawasi pemerintahan desa. Pasal 55 dalam peraturan tersebut menyebutkan sejumlah fungsi BPD yang berkaitan dengan kepala Desa, yaitu membahas dan menyepakati Rancangan Peraturan Desa bersama Kepala Desa, menampung dan menyalurkan aspirasi masyarakat Desa, serta melakukan pengawasan kinerja Kepala Desa. Biaya operasional pelaksanaan tugas dan fungsi BPD bersumber dari Anggaran Pendapatan dan Belanja Desa (APBDes). 
Melalui peraturan itu pula, menuntut perubahan dalam tata kelola organisasi Badan Pemusyawaratan Desa khususnya di Desa Sepakat Kecamatan Loa Kulu Kabupaten Kutai Kartanegara, hal ini yang mendorong peneliti meneliti tata kelola organisasi Badan Pemusyawaratan Desa Sepakat.

\section{Solusi Masalah}

Pendekatan yang diterapkan memuat analisis deskriptif-kualitatif. Proses disini memfokuskan menjadi empat dimensi. Pokok bahasan pertama, struktur organisasi BPD Desa Sepakat. Kedua, pembagian tugas pokok dan fungsi setiap anggota BPD. Ketiga, SOP pelaksanaan kegiatan. Keempat, Pengawasan BPD. Melalui wawancara mendalam, output-nya adalah mendapat beberapa unit, memeriksa data yang diperoleh, mereduksi data, penerapan data yaitu pengolahan data, dan menganalisa, hingga menarik kesimpulan tentang objek yang diamati.

\section{Metode Pelaksanaan}

\subsection{Area dan Khalayak Sasaran}

Lokasi pengabdian kepada masyarakat ini mencakup di Desa Sepakat, Kecamatan Loa Kulu, Kabupaten Kutai Kartanegara, Provinsi Kalimantan Timur. Khalayak sasaran dengan melibatkan Kepala Desa Sepakat, BPD, dan aparat Desa yang terkait. Lingkup pelaksanaan berfokus pada pengelolaan aset Desa.

\subsection{Mekanisme Pengabdian}

Alur pengabdian ditunjang dengan analisis data yang diterapkan pada saat wawancara berlangsung. Dalam praktiknya, mengikuti model analisis interaktif milik Miles et al. (2014) dengan empat unsur. Adapun tahapan-tahapan identifikasi secara kualitatif bermuara pada analisis interaksi (simak Gambar 1).

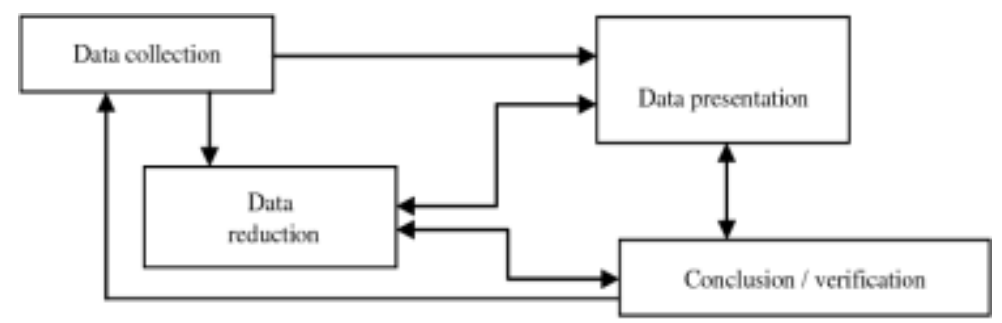

Gambar 1. Visualisasi pada Proses Interaktif

Sumber: dikembangkan dari Bargate (2014).

Sesi pertama adalah pengumpulan data, dimana kami menggali data di lapangan (objek penelitian) baik dengan wawancara, observasi, dan dokumentasi telah dilakukan pencatatan. Catatan yang dimaksud adalah catatan deskriptif dan reflektif. Catatan deskriptif merupakan catatan alami dari segala sesuatu yang dilihat, didengar, disaksikan, dan dialami sendiri oleh peneliti. Disatu sisi, catatan reflektif merupakan catatan yang berisi kesan, komentar, pendapat, dan tafsiran peneliti tentang fakta dan temuan baru yang ditemukan, dijumpai, dan menjadi bahan rencana pengumpulan data ditahap berikutnya (Akinyode \& Khan, 2018).

Sesi kedua yakni reduksi data. Data yang dikumpulkan kemudian direduksi untuk memilih data yang relevan dan sesuai dengan fokus kegiatan. Kemudian data atau informasi yang 
didapat disederhanakan, disusun secara sistematis untuk menjabarkan temuan yang penting dan relevan. Tahap reduksi data digunakan untuk menggolongkan dan memfokuskan data serta membuang data yang tidak perlu, sehingga mudah untuk menarik kesimpulan.

Sesi ketiga yaitu penyajian data. Setelah dilakukan reduksi data, maka langkah seterusnya ialah penyajian data. Dengan melalui penyajian data tersebut, maka data terorganisasikan dalam pola hubungan, sehingga akan mudah dipahami. Dalam penelitian kualitatif, penyajian data bisa dilakukan dalam bentuk uraian singkat, gambar, dan deskripsi tambahan. Penyajian data juga akan membantu dalam mempermudah dalam hal pemahaman apa yang sedang terjadi, merencanakan kelanjutan dari proses penganalisisan. Penyajian data dalam penelitian ini dipaparkan dengan bentuk teks atau tulisan yang berbentuk narasi.

Terakhir, adalah sesi keempat mengenai verifikasi analisis. Bagian ini terkait dengan seberapa besar kumpulan catatan lapangan dan pengkodean yang dilaksanakan peneliti. Hasil penelitian juga ditarik kesimpulan selama penelitian berlangsung. Penarikan kesimpulan itu mungkin sesingkat pemikiran kembali yang melintas dalam pikiran penganalisis selama peneliti menulis, sutau tinjauan ulang pada catatancatatan lapangan.

Selanjutnya, data-data tersebut dikumpulkan dari tiga kegiatan melalui wawancara ke beberapa informan, dari pengamatan atau observasi dilapangan, dan hasil dokumentasi baik rekaman suara, rekaman video, maupun pengambilan gambar. Data dari hasil ketiga kegiatan diatas, yang tidak sesuai dengan fokus penelitiann akan dilakukan penghapusan agar fokus penelitian tidak semakin melebar. Kemudian, data yang sudah sesuai dengan fokus penelitian akan disajikan dengan menarik. Ini berfungsi agar informasi yang didapat dalam penelitian ini bisa dibaca dan dipahami dengan mudah (Verdinelli \& Scagnoli, 2013). Setelah data benarbenar lengkap, maka akan dilakukan penarikan kesimpulan

\section{Hasil Pelaksanaan dan Diskusi}

Laporan pengabdian masyarakat ini hanya menjangkau sejauh mana atau gambaran tentang pengelolaan aset Desa di Desa Sepakat yang diadakan pada hari Kamis, 15 Juli 2021. Pertemuan semacam Focus Group Discussions (FGD) dengan Kepala Desa Sepakat dan ketua BPD Desa Sepakat melalui zoom. Time-line diawali dengan pemaparan terkait profil Desa Sepakat oleh Kepala dan Seketaris Desa. Pada sesi selanjutnya, dosen sebagai pelaksana PKM memberikan ceramah dengan materi yang sudah diberikan oleh pengelola Laboratorium Inkubator Bisnis dibawah naungan Fakultas Ekonomi dan Bisnis (Universitas Mulawarman). Tampak Gambar 2 sebagai bukti pemaparan materi oleh narasumber dari pihak akademisi (Dr. Juliansyah Roy dan Selly Swandari).

Di Undang-Undang Nomor 6 Tahun 2014 tentang Desa (pasal 54) merepresentasikan bahwa musyawarah Desa merupakan forum pemusyawaratan yang diikuti oleh sebuah Badan yang Permusyawaratan Desa (BPD), Pemerintah Desa (PD), dan unsur masyarakat Desa yang bermanfaat untuk memusyawarahkan hal yang bersifat strategis dalam penyelenggaraan Pemerintah Desa (Setyaningrum \& Wisnaeni, 2019). BPD Sepakat juga telah diatur dalam Peraturan Daerah Nomor 11 tahun 2020 tentang Pedoman Badan Permusyawaratan Desa di Kabupaten Kutai Kartanegara. Berkaitan dengan penyelenggaraan dalam pemerintahan di Desa, pemerintah Desa sebagai penggerak masyarakat untuk dapat berpartisipasi dalam pembangunan fisik Desa dan penyelenggaraan administrasi Desa, maka setiap keputusan yang diambil harus didasarkan atas musyawarah Desa untuk mencapai keputusan bersama. 


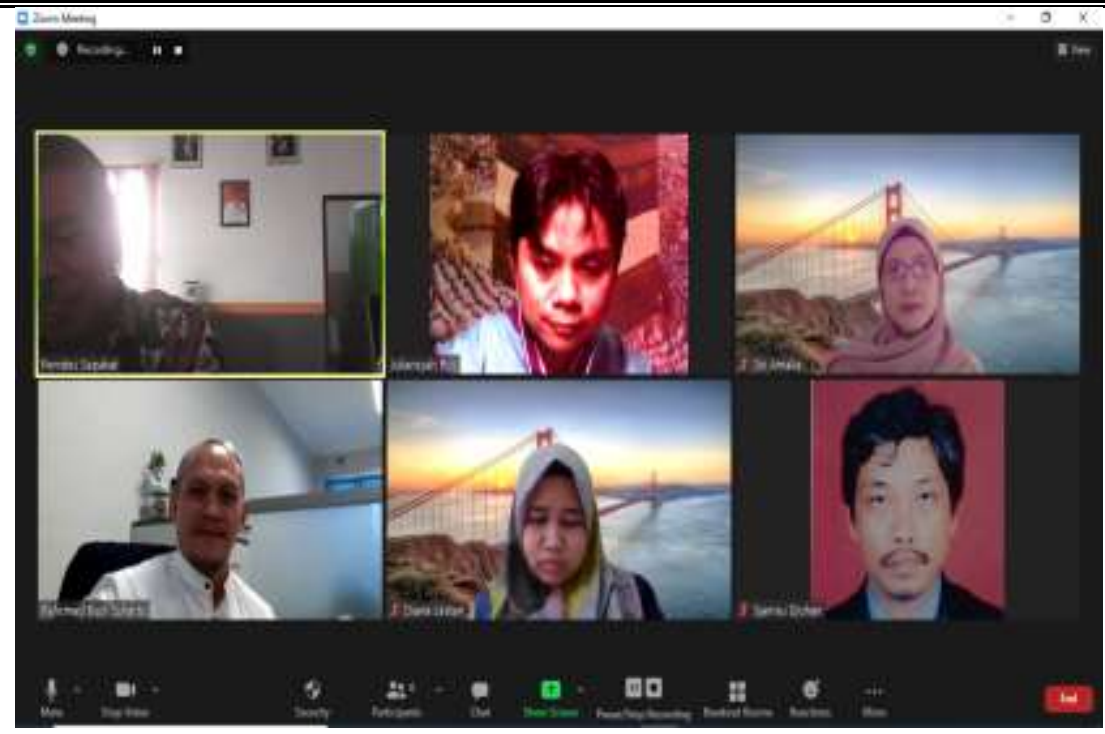

Gambar 2. Sharing-Knowledge dalam Pertemuan

Sumber: Pelaksana kegiatan (2021).

Sebab itu, perencanaan pembangunan desa dilaksanakan pada musyawarah pembangunan desa antara pemerintah Kabupaten atau Kota dengan aparatur desa terkait. Dalam hal ini pemerintah Desa dan tentu BPD berfungsi untuk menampung dan menyalurkan aspirasi masyarakat dalam memenuhi kebutuhan hidup dan penghidupannya (Guntoro \& Mutholib, 2015). Fenomena menjadi persoalan dalam hal ini apakah BPD telah benar-benar melaksanakan tugas pokok dan fungsinya dalam perencanaan pembangunan Desa sesuai dengan yang diamanatkan oleh Undang-Undang, ataukah ada faktor-faktor lain yang menunjang perencanaan pembangunan Desa.

Namun di sisi lain, meskipun memiliki posisi yang sangat strategis, BPD masih belum optimal dalam menjalankan fungsinya (Perdana et al., 2017). Gejala ini tampak pada hasil pra penelitian atas pengamatan terhadap Desa Sepakat. Sebagai institusi demokrasi Desa, BPD berhak untuk mengawasi penyelenggaran pemerintahan, menyatakan pendapat atas urusan administrasi pemerintahan Desa, dan memperoleh biaya operasional untuk melaksanakan fungsi maupn tugas dari APBDes.

Mayoritas masyarakat di Desa Sepakat, mata pencariannya masyarakatnya pada disektor perikanan. Sektor-sektor lain yang masih potensial dapat dikembangkan di Desa Sepakat adalah sektor pertanian, namun sistem pengolahan tanah di Desa Sepakat belum mencerminkan pola tanam pengolahan tanah pertanian terpadu, sehingga tingkat produktifitas. Hasil yang dicapai dari sektor pertanian belum optimal. Dikesempatan lain, Salim (2016) menyoroti hambatan lain terkait pengembangan sektor pertanian, masih kurangnya sumber daya manusia yang mampu mengelola dan memanfaatkan sektor pertanian.

Dalam diskusi, sebagaimana disampaikan oleh Kepala Desa Sepakat dan Ketua BPD Desa Sepakat, jika secara umum BPD sudah menjalankan fungsinya sebagai pengawas dan penyerap aspirasi masyarakat Desa sepakat. Akan tetapi, dalam perjalanannya masih ditemukan beberapa hambatan seperti Struktur organisasi yang ada perlu diperjelas dengan pembagian tugas pokok dan fungsi setiap anggota dan/atau bidang dalam BPD. Bagi SOP, 
setiap kegiatan harus dibuat sebagai dasar pelaksanaan kegiatan. Secara berkala, BPD harus membuat laporan kinerja BPD dalam kaitan kinerja kepala Desa Sepakat dan BPD memerlukan tempat sekretariat BPD secara permanen/tetap, bukan menyewa.

Mengacu potensi infrastruktur di Desa Sepakat, pelaksana PKM mengusulkan perbaikan dalam penggunaan dan pengelolaanya agar menjadi produktif dan menghasilkan nilai tambah dikemudian hari. Sejauh ini, beberapa bagian kepemilikan berdasarkan observasi pelaksana terdiri dari dua klasifikasi (milik warga dan milik pemerintah).

Infrastruktur kepemilikan warga pada umumnya berbentuk rumah tempat tinggal dengan bangunan sebagian besar berbahan dasar kayu yang terletak dibantaran Sungai Mahakam. Disatu sisi, ssebagian lainnya berbentuk semi permanen yang berada disebelah timur Jalan poros Samarinda-Tenggarong hingga perbatasan wilayah Desa Sepakat dengan Desa Ponoragan dan Sumber Sari. Adapun Infrastruktur milik pemerintah pada umumnya berbentuk permanen berupa bangunan perkantoran, sekolah, jalan, parit pasangan, dan sebagainya.

Berbicara tentang aset Desa atau kekayaan Desa adalah barang atau bukan barang yang berasal dari kekayaan asli Desa, dibeli atau diperoleh atas beban Anggaran Pendapatan dan Belanja Desa atau perolehan hak lainnya yang sah. Aset Desa yang ada harus dikelola dengan baik, yang dimana pada akhirnya akan dapat dirasakan pemanfaatannya oleh masyarakat sekitar. Pengelolaan tidak terlepas dari implementasi manajerial, dimana ada proses untuk mewujudkan tujuan yang diinginkan melalui aspek-aspeknya antara lain planning, organizing, actuating, dan controlling (Maria et al., 2021). Kekayaan Desa dikelola oleh pemerintah Desa dan dimanfaatkan sepenuhnya untuk kepentingan penyelenggaraan pemerintahan, pembangunan, dan pelayanan masyarakat Desa (Indriani et al., 2021).

Kepala Desa sebagai pemegang kekuasaan pengelolaan kekayaan milik Desa. Dalam melaksanakan kekuasaan pengelolaan kekayaan, mereka dapat menguasakan sebagian kekuasaannya kepada perangkat Desa lainnya (Brudney, 1982). Pengelolaan kekayaan milik Desa merupakan rangkaian kegiatan mulai dari perencanaan, pengadaan, penggunaan, pemanfaatan, pengamanan, pemeliharaan, penghapusan, pemindah tanganan, penatausaan, pelaporan, penilaian, pembinaan, pengawasan, dan pengendalian kekayaan milik Desa.

\section{Kesimpulan}

Dari uraian yang telah dipresentasikan terdahulu, maka dapat diambil dua kesimpulan vital. Pertama adalah tata kelola BPD Sepakat dikelola berdasarkan Peraturan Daerah Nomor 11 Tahun 2020 tentang Pedoman Badan Permusyawaratan Desa Kabupaten Kutai Kartanegara. Artinya, aturan ini menjadi pondasi dalam keberlangsungan dan eksistensi Desa Sepakat. Kedua, dalam perjalanannya masih ditemukan beberapa hambatan seperti struktur organisasi yang ada perlu diperjelas terutama dalam pembagian tugas pokok dan fungsi setiap anggota dan/atau bidang dalam BPD. Lalu, SOP dari setiap kegiatan harus dibuat sebagai dasar pelaksanaan kegiatan. Secara berkala BPD harus membuat laporan kinerja BPD dalam kaitan kinerja kepala desa sepakat. BPD juga memerlukan tempat sekretariat secara permanen atau bersifat tetap, bukan menyewa.

Dari PKM ini, dapat terlihat bahwa pengelolaan Desa tidaklah mudah. Diperlukan konsistensi dan serangkaian proses panjang yang dilakukan oleh sekelompok orang dalam arti pengelolaan aset Desa. Aparatur Desa berwenang penuh pada tahap perencanaan, pengorganisasian, pelaksanaan, dan pengawasan dengan memanfaatkan potensi yang ada 
demi tercapainya sebuah nilai dan tujuan.

\section{Ucapan Terima Kasih}

Kami juga berterima kasih dan bersyukur terhadap hibah internal yang diberikan dari Program Doktor (S3) Ilmu Ekonomi, Fakultas Ekonomi dan Bisnis, Universitas Mulawarman.

\section{Referensi}

Akinyode, B. F., \& Khan, T. H. (2018). Step by step approach for qualitative data analysis. International Journal of Built Environment and Sustainability, 5(3), 163-174. https://doi.org/10.11113/ijbes.v5.n3.267

Bargate, K. (2014). Interactive qualitative analysis - a novel methodology for qualitative research. Mediterranean Journal of Social Sciences, 5(20), 11-19. http://dx.doi.org/10.5901/mjss.2014.v5n20p11

BPS Kabupaten Kutai Kartanegara. (2020). Kecamatan Loa Kulu dalam angka 2020. Samarinda: Mahendra Mulya. Diambil dari https://kukarkab.bps.go.id/publication/2020/09/28/e5b2f27c5dfd4ae5ef41e47f/kecamatan-loakulu-dalam-angka-2020.html

Brudney, V. (1982). The independent director: Heavenly City or Potemkin Village?. Harvard Law Review, 95(3), 597-659. https://doi.org/10.2307/1340594

Darma, D. C., Maria, S., \& Wijayanti, T. C. (2021). Kinerja aparatur dalam memediasi kreativitas dan inovasi terhadap keberhasilan penerapan e-kelurahan. Aksiologiya: Jurnal Pengabdian Kepada Masyarakat, 5(3), 401-410. http://dx.doi.org/10.30651/aks.v5i3.4004

Dina, N. Z., Firdaus, A. A., \& Yunardi, R. T. (2020). Pelatihan pembuatan website menggunakan elementor pada produk Bumdes Banjarworo, Kabupaten Tuban sebagai sarana promosi. Jurnal Nasional Pengabdian Masyarakat, 1(1), 24-30. https://doi.org/10.47747/pengabdiankepadamasyarakat.v1i1.109

Endah, K. (2018). Penyelenggaraan pemerintahan Desa menurut Undang-Undang Nomor 6 Tahun 2014 tentang Desa. Dinamika: Jurnal Ilmu Administrasi Negara, 5(1), 76-82. http://dx.doi.org/10.25157/dinamika.v5i1.1224

Faedlulloh, D. (2018). BUMDes dan kepemilikan warga: membangun skema organisasi partisipatoris. Journal of Governance, 3(1), 1-17. http://dx.doi.org/10.31506/jog.v3i1.3035

Giampiccoli, A., \& Saayman, M. (2018). Community-based tourism development model and community participation. African Journal of Hospitality Tourism and Leisure, 7(4), 1-27. Diambil dari https://www.ajhtl.com/uploads/7/1/6/3/7163688/article_16_vol_7_4_2018.pdf

Guntoro, R., \& Mutholib, A. (2015). Pelaksanaan fungsi badan permusyawaratan Desa (BPD) dalam penyelenggaraan pemerintahan di Desa pananjung kecamatan pangandaran Kabupaten Pangandaran. Moderat: Jurnal Ilmiah Ilmu Pemerintahan, 1(1), 65-76. http://dx.doi.org/10.25147/moderat.v1i1.2933

Ilmi, Z. (2021). Potret aspek pasar dan pemasaran untuk BUMDes 'Karya Mandiri: (Desa Sepakat, Kabupaten Kutai Kartanegara). Jurnal Pustaka Mitra (Pusat Akses Kajian Mengabdi 
\begin{tabular}{lllll}
\hline \hline Terhadap & Masyarakat $),$ & $l(1)$, & $43-48$. & Diambil
\end{tabular} https://jurnal.pustakagalerimandiri.co.id/index.php/pustakamitra/article/view/38

Indriani, M., Nadirsyah, N., Fuadi, R., \& Evayani, E. (2021). Can siskeudes support village governance in Aceh Province of Indonesia?. Cogent Business \& Management, 7(1), 1743617. https://doi.org/10.1080/23311975.2020.1743617

Mafruhah, I., Mulyani, N. S., Istiqomah, N., \& Ismoyowati, D. (2018). Development of ecotourism based on community empowerment (a case study of Kebumen Regency). Jurnal Ekonomi Pembangunan: Kajian Masalah Ekonomi dan Pembangunan, 19(2), 196-206. https://doi.org/10.23917/jep.v19i2.6996

Maria, S., Lestari, D., Rochaida, E., et al. (2021). Self-efficacy, organizational commitment, and employee performance - from public office. Cactus: Tourism Journal for Research, Education, Culture and Soul, 3(1), 6-15. http://dx.doi.org/10.24818/CTS/3/2021/1.01

Milasari, L. A. (2021). Analisis pemilihan lokasi tempat pembuangan sampah di Kecamatan Loa Kulu, Kabupaten Kutai Kartanegara. Jurnal Kacapuri: Jurnal Keilmuan Teknik Sipil, 4(1), 298-305. http://dx.doi.org/10.31602/jk.v4i1.5277

Miles, M. B, Huberman, A. M., \& Saldana, J. (2014). Qualitative data analysis: a methods sourcebook, Ed. 3. Thousand Oaks: Sage Publications.

Perdana, K. A., Sinarwati, N. K., \& Herawati, N. T. (2018). Perilaku legislatif badan permusyawaratan Desa dalam praktik penganggaran sektor publik (APBDes) Desa Subuk. Jurnal Ilmiah Mahasiswa Akuntansi, 8(2), 1-8. http://dx.doi.org/10.23887/jimat.v8i2.10953

Pradana, M. Y., \& Istriyani, R. (2020). Sepakat-sepaket: modal sosial politik masyarakat kalitekuk dalam mewujudkan Desa wisata. Jurnal Ilmiah Ilmu Sosial, 6(2), 138-149. http://dx.doi.org/10.23887/jiis.v6i2.28466

Rahmawati, E. (2020). Analisis pengelolaan badan usaha milik Desa (BUMDesa) di Kabupaten Bandung Barat. Jurnal Ilmiah Ekonomi Bisnis, 25(1), 1-13. http://dx.doi.org/10.35760/eb.2020.v25i1.2386

Salim, M. N. (2016). Bertani diantara himpitan tambang (belajar dari petani Kutai Kartanegara). BHUMI: Jurnal Agraria dan Pertanahan, 2(1), 31-47. https://doi.org/10.31292/jb.v2i1.230

Setyaningrum, C. A., \& Wisnaeni, F. (2019). Pelaksanaan fungsi badan permusyawaratan Desa terhadap penyelenggaraan pemerintahan Desa. Jurnal Pembangunan Hukum Indonesia, 1(2), 158-170. https://doi.org/10.14710/jphi.v1i2.158-170

Suharto, D. G. (2015). Penyelenggaraan pemerintahan Desa dalam perspektif desentralisasi administratif dan desentralisasi politik. Jurnal Bina Praja: Journal of Home Affairs Governance, 4(3), 153-160. https://doi.org/10.21787/jbp.04.2012.153-160

Sulaiman, A. I., Lubis, D. P., Susanto, D., \& Purnaningsih, N. (2016). Characteristic, aspirations, information media in development planning consultation forums at the Banjar City, West Java Province. Jurnal Penelitian Komunikasi, 19(1), 69-82. https://doi.org/10.20422/jpk.v19i1.54

Verdinelli, S., \& Scagnoli, N. I. (2013). Data display in qualitative research. International Journal of Qualitative Methods, 12, 359-381. https://doi.org/10.1177/160940691301200117 
Yusuf, Y., \& Elvira, M. (2016). Perubahan status sosial ekonomi masyrakat di Dusun Sepakat Desa Ganting Damai Kecamatan Salo Kabupaten Kampar. Jurnal Online Mahasiswa Fakultas Ilmu Sosial dan Ilmu Politik Universitas Riau, 3(2), 1-15. Diambil dari https://jom.unri.ac.id/index.php/JOMFSIP/article/view/10304

Zainurossalamia, S., Amalia, S., Darma, D. C., \& Azis, M. (2021). Spurring economic growth in terms of happiness, human development, competitiveness and global innovation: the ASEAN case. ASEAN Journal on Science and Technology for Development, 38(1), 1-6. https://doi.org/10.29037/ajstd.653

\section{Copyrights}

Copyright for this article is retained by the author(s), with first publication rights granted to the journal.

This is an open-access article distributed under the terms and conditions of the Creative Commons Attribution license (http://creativecommons.org/licenses/by/4.0/) 